\title{
New alum
}

\section{Dr. Mohr}

To cite this article: Dr. Mohr (1841) New alum, Philosophical Magazine Series 3, 19:121, 93-93, DOI: $10.1080 / 14786444108650375$

To link to this article: http://dx.doi.org/10.1080/14786444108650375

$$
\text { 册 Published online: } 01 \text { Jun } 2009 .
$$

Submit your article to this journal 전

LII Article views: 2

Q View related articles ¿ 
NEW ALUM. BY DR, MOHR.

A variety of alum has been for some time introduced into Germany, which is recommended as containing the principles necessary to dyeing and calico printing in a state of great concentration; this quality is represented as rendering its use more advantageous, and less expensive in carriage. This alum has not the slightest resemblance to common potash alum; it exists in flat quadrangular tables, which are slightly transparent, and dissolve very readily in water; the taste of this salt is sweetish, acid, and aluminous, and much more distinctly so than common alum; when heated in a crucible it swells, and eventually becomes a gummy mass, which, when more strongly heated, gives out sulphuric vapours. Nevertheless the mass which has been heated to redness is entirely and readily soluble in water. If pulverized sulphate of potash be thrown into a concentrated solution of this alum, a crust of common alum is quickly formed. The usual reagents prove that it contains sulphuric acid, alumina, and a small quantity of potash, but no ammonia. M. Mohr found it to consist of

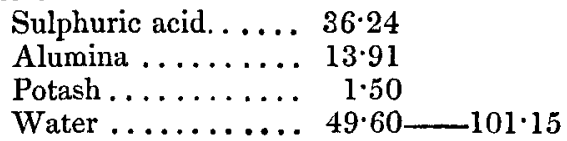

This composition shows that the alum in question is, properly speaking, merely sulphate of alumina with an excess of acid, and combined with water of crystallization. The small quantity of sulphate of potash shows the origin of this salt, it being probably prepared with pulverized and calcined pipe-clay and sulphuric acid not completely concentrated. This new alum is entirely free from iron. -Journal de Pharmacie, t. xxvi. p. 633.

\section{ON THE SUPPOSED HYDRATE OE PHOSPHORUS. BY M. MAR-} CHAND.

M. Pelouze was the first chemist who supposed that the white crust which covers phosphorus that has been long kept, is a hydrate of this substance: M. H. Rose regards it merely as a modification of the state of aggregation: M. Mulder believes that it is a compound of oxide of phosphorus and phosphuretted hydrogen. He has remarked that the white sticks of phosphorus become of a red colour in aërated distilled water, and he immediately obtained a similar white substance by subjecting red oxide of phosphorus to the action of phosphuretted hydrogen.

M. Marchand being desirous of settling the question, pressed a quantity of the white crust, strongly, between folds of filtering paper, as had been done by $M$. Rose; he then placed it in a capsule over sulphuric acid in vacuo, and allowed it to remain so for several days. On the first day a feeble light was perceptible; but it soon disappeared: and when access of air was allowed the mass inflamed as if it had been phosphorus under similar circumstances.

A fresh quantity of the white crust was again dried over sulphuric acid, but under a receiver without a vacuum. M. Marchand placed 